Boise State University

ScholarWorks

4-1-2012

\title{
Size, Surface Structure, and Doping Effects on Ferromagnetism in $\mathrm{SnO}_{2}$
}

Gordon A. Alanko

Boise State University

Aaron Thurber

Boise State University

Charles Hanna

Boise State University

Alex Punnoose

Boise State University 


\title{
Size, Surface Structure, and Doping Effects on Ferromagnetism in $\mathrm{SnO}_{2}$
}

\author{
Gordon A. Alanko, Aaron Thurber, Charles B. Hanna, and Alex Punnoose \\ Boise State University
}

\begin{abstract}
The effects of crystallite size, surface structure, and dopants on the magnetic properties of semiconducting oxides are highly controversial. In this work, $\mathrm{Fe}: \mathrm{SnO}_{2}$ nanoparticles were prepared by four wet-chemical methods, with Fe concentration varying from 0-20\%. Samples were characterized by x-ray diffraction (XRD), x-ray photoelectron spectroscopy (XPS), transmission electron microscopy (TEM), and vibrating sample magnetometry (VSM). Analysis confirmed pure single-phase cassiterite with a crystallite size of $2.6 \pm 0.1 \mathrm{~nm}$ that decreased with increasing $\mathrm{Fe} \%$. Fe concentration was confirmed from XPS studies, with $\mathrm{Fe}$ ions in the 3+ oxidation state. Pure $\mathrm{SnO}_{2}$ showed highly reproducible weak magnetization that varied significantly with synthesis method. Interestingly, doping $\mathrm{SnO}_{2}$ with $\mathrm{Fe}<2.5 \%$ produced enhanced magnetic moments in all syntheses; the maximum of $1.6 \times 10^{-4} \mu_{\mathrm{B}} / \mathrm{Fe}$ ion at $0.1 \% \mathrm{Fe}$ doping was much larger than the $2.6 \times 10^{-6} \mu_{\mathrm{B}} / \mathrm{Fe}$ ion of pure Fe oxide nanoparticles synthesized under similar conditions. At $\mathrm{Fe} \geq 2.5 \%$, the magnetic moment was significantly reduced. This work shows that (i) pure $\mathrm{SnO}_{2}$ can produce an intrinsic ferromagnetic behavior that varies with differences in surface structure, (ii) very low Fe doping results in high magnetic moments, (iii) higher Fe doping reduces magnetic moment and destroys ferromagnetism, and (iv) there is an interesting correlation between changes in magnetic moment, band gap, and lattice parameters. These results support the possibility that the observed ferromagnetism in $\mathrm{SnO}_{2}$ might be influenced by modification of the electronic structure by dopant, size, and surface structure.
\end{abstract}

\section{Introduction:}

Nanoscale Tin oxide $\left(\mathrm{SnO}_{2}\right)$ is a promising candidate for multiple applications, including optoelectronics, photocatalysis, gas detection, and spintronics. ${ }^{1-3} \mathrm{SnO}_{2}$ has been extensively researched as a dilute magnetic semiconductor since Dietl ${ }^{4}$ predicted room temperature ferromagnetism (RTFM) in $\mathrm{Mn}$-doped $\mathrm{ZnO}^{4}$, and several theoretical models propose to explain observations of $\mathrm{RTFM}$ in $\mathrm{SnO}_{2} \cdot{ }^{5-7}$ Recent computational work predicts RTFM in $\mathrm{SnO}_{2}$ due to nitrogen substitution ${ }^{8}$, surface carbon ${ }^{9}$, or non-magnetic dopants. ${ }^{10,11}$ Raman et al. proposed RTFM due to tin vacancies ${ }^{12}$, but $\mathrm{V}_{\mathrm{sn}}$ is not considered thermodynamically favorable. ${ }^{13}$ Existing literature includes conflicting reports about RTFM in undoped nanoparticles (NPs) ${ }^{14}$ and its dependence on transition metal doping concentration $^{15,16}$ and crystallite size. ${ }^{17}$ A recent report on RTFM in pure ZnO NPs capped with organic ligands highlighted the importance of surface structure ${ }^{18}$. For these reasons, we have prepared an extensive set of high quality $\sim 2.5 \mathrm{~nm} \mathrm{Sn}_{1-\mathrm{x}} \mathrm{Fe}_{\mathrm{x}} \mathrm{O}_{2}$ NPs, using a variety of methods to study the impact of varying precursors, synthesis methods, surface structure, and Fe doping on the magnetic properties.

\section{Experimental:}

Four different pure $\mathrm{SnO}_{2}$ synthesis methods were adapted for Fe doping. In the first preparation, denoted $\mathbf{S n O}_{2}-\mathbf{I}$, Tin (IV) acetate $\left(\mathrm{Sn}\left(\mathrm{C}_{2} \mathrm{H}_{4} \mathrm{OH}\right)_{4}\right.$, Iron (II) acetate $\left(\mathrm{Fe}\left(\mathrm{C}_{2} \mathrm{H}_{4} \mathrm{OH}\right)_{2}\right.$ and Urea $\left(\mathrm{C}_{2} \mathrm{O}_{2}\left(\mathrm{NH}_{3}\right)_{2}\right)$ were used as precursor materials for synthesis. In the second preparation, denoted $\mathbf{S n O}_{2}-\mathbf{I I}$, precursors were Sodium stannate $\left(\mathrm{NaSnO}_{3} \cdot 3 \mathrm{H}_{2} \mathrm{O}\right)$, Iron (II) acetate, and Urea. In the third preparation, denoted $\mathbf{S n O}_{2}-\mathbf{I I I}$, precursors were Tin (IV) chloride pentahydrate $\left(\mathrm{SnCl}_{4} \cdot 5 \mathrm{H}_{2} \mathrm{O}\right)$, Iron (III) chloride $\left(\mathrm{FeCl}_{3}\right)$, and Urea. In the fourth preparation, denoted $\mathbf{S n O}_{2}$ $\boldsymbol{I V}$, precursors were Tin (IV) acetate and Iron (II) acetate. Additionally, a pure iron oxide sample was prepared from the respective Iron (II) precursor in each reaction system. All syntheses were carried out at $90{ }^{\circ} \mathrm{C}$ in nanopure water for 90 minutes, with the exception of $\mathrm{SnO}_{2}-\mathrm{IV}$, which was synthesized in benzyl alcohol at a temperature of $100{ }^{\circ} \mathrm{C}$. 
All samples were removed from solution by centrifuging at $21000 \mathrm{rpm}$, after which the samples were dried in an oven at $50{ }^{\circ} \mathrm{C}$. Detailed characterization studies using XRD, TEM, XPS, VSM and UV-vis photospectrometery were carried out following procedures described previously. ${ }^{15}$ Pure undoped samples were prepared in each method as well as Fe-doped $\mathrm{Sn}_{1-\mathrm{x}} \mathrm{Fe}_{\mathrm{x}} \mathrm{O}_{2}$ with $\mathrm{x}=0.01,0.05$, and 0.10. After initial magnetic characterization, $\mathrm{SnO}_{2}$-II was chosen for additional detailed doping studies with $\mathrm{x}=0.001,0.005,0.025,0.075,0.15$, and 0.20 . Hereafter $\mathrm{Fe}$ content will be referred to as atomic \% $\left(\%=100 * x\right.$ in $\left.\mathrm{Sn}_{1-\mathrm{x}} \mathrm{Fe}_{\mathrm{x}} \mathrm{O}_{2}\right)$.

\section{Results and Discussion:}

Representative XRD patterns are shown in Fig. 1a. Crystallite size and lattice parameters were obtained by simultaneous fitting (Fig. 1b) and applying the Scherrer equation ${ }^{15}$. XRD shows pure single-phase cassiterite $\mathrm{SnO}_{2}$ that gradually decreases in crystallite size with increasing Fe\% (Fig. 1c) from $2.6 \pm 0.1 \mathrm{~nm}$ at $0 \%$ Fe to $2.3 \pm 0.1 \mathrm{~nm}$ at $20 \% \mathrm{Fe}$, similar to previous studies of transition metal doped oxides. ${ }^{19,20}$ Williamson-Hall analysis shows an increase in lattice strain with increasing $\mathrm{Fe} \%$, indicative of the structural changes that Fe doping introduces. Lattice parameter $\mathrm{c}$ and lattice volume $\mathrm{V}$ decreased rapidly for Fe doping $<2.5 \%$ and moderately for $\mathrm{Fe} \geq 2.5 \%$ (Fig. $1 \mathrm{~d}$ and 1e)This result suggests that $\mathrm{Fe}^{3+}(\mathrm{r}=132 \mathrm{pm} \text {, assuming low-spin })^{21}$ might be substituting for $\mathrm{Sn}^{4+}(\mathrm{r}=139 \mathrm{pm})$ in the crystal lattice, causing a slight contraction of $c$ because of the smaller cationic radius of Fe, while lattice parameter $a$ expands due to charge-compensating oxygen vacancies. ${ }^{22}$ This behavior is similar to that studied for several other transition metal dopants in $\mathrm{SnO}_{2} \cdot{ }^{23}$ At $>2.5 \%$, additional interstitial incorporation of Fe ions and/or other processes might be responsible for the observed slowdown in the lattice contraction. A pure iron oxide sample (prepared identically to $\mathrm{SnO}_{2}$-II but without Tin acetate) had extremely small, poorly crystallized particulates that generally matched reported peak positions for $2 \mathrm{~nm}$ defective ferrihydrite $\left(5 \mathrm{Fe}_{2} \mathrm{O}_{3} * \mathrm{H}_{2} \mathrm{O}\right){ }^{24,25}$.

In XPS analysis the Fe3p signal was used instead of Fe2p (which is overlapped by Sn3p). The Fe3p signal increased with increasing $\mathrm{Fe} \%$ (Fig 2a). $\mathrm{Sn}_{1-\mathrm{x}} \mathrm{Fe}_{\mathrm{x}} \mathrm{O}_{2}$-II had a Fe peak at $56.1 \mathrm{eV}$, which is higher than the reported values of metallic $\mathrm{Fe}(53 \mathrm{eV})$ and common Fe oxides including $\mathrm{Fe}_{3} \mathrm{O}_{4}(53.9 \mathrm{eV})$, $\mathrm{FeO}(54.9 \mathrm{eV})$, and $\mathrm{Fe}_{2} \mathrm{O}_{3}(55.4 \mathrm{eV}) .{ }^{26}$ Spinorbit splitting in the $\mathrm{Fe} 2 \mathrm{p}$ region is $13.5 \mathrm{eV}$, which gives an oxidation state of $\mathrm{Fe}^{3+}$ (not shown). The similarlyprepared pure Fe oxide had a Fe peak at $55.6 \mathrm{eV}, 0.5 \mathrm{eV}$ lower than that in $\mathrm{Sn}_{1-\mathrm{x}} \mathrm{Fe}_{\mathrm{x}} \mathrm{O}_{2}$-II and closest to reported values for $\mathrm{Fe}_{2} \mathrm{O}_{3} \cdot{ }^{27}$ This chemical state information indicates that $\mathrm{Fe}$ in our $\mathrm{Sn}_{1-\mathrm{x}} \mathrm{Fe}_{\mathrm{x}} \mathrm{O}_{2}$ is not present as a common iron oxide. Determining $\mathrm{Fe} \%$ from XPS data was complicated by the proximity of the Fe and Sn peaks, with measured concentrations slightly lower than nominal; since XPS is extremely surface-sensitive, the small difference from nominal concentration could indicate a tendency of Fe ions to concentrate within the center of the particles. No transition metal impurities were found by XPS, despite a detailed high-resolution scan of each sample.

Optical bandgap measurements (Fig. 2b) show significant modification of the electronic structure of both pure and Fe-doped $\mathrm{SnO}_{2}$ NPs. All samples show a marked blue shift from the bulk bandgap $\left(\mathrm{E}_{\mathrm{g}}\right)$ of $3.6 \mathrm{eV}^{28}$, while Fe doping redshifts $E_{g}$ slightly (Fig. 2c). The pure Fe oxide sample shows increased absorbance in the region 200-500 nm that has also been observed for $\mathrm{Fe}$ in other systems ${ }^{29}$. In the doped samples, increased $\mathrm{Fe} \%$ resulted in increased absorbance in the region 320-500 $\mathrm{nm}$ that has been attributed to oxygen vacancies. ${ }^{30}$. The inset (Fig 2c) shows a decrease $\mathrm{E}_{\mathrm{g}}$ with $\mathrm{Fe} \leq 2.5 \%$ in all synthesis methods, whereas obvious differences between methods appeared at higher $\mathrm{Fe} \%$. These results differ from expectations of increasing $\mathrm{E}_{\mathrm{g}}$ with decreasing particle size and/or lattice parameters: this unconventional behavior could be a result of Fe doping (substitutional and interstitial), chargecompensating oxygen vacancies, very small crystallite size $(<3 \mathrm{~nm})$ and/or structural disorder caused by these effects. Further experiments and modeling are planned to elucidate the electronic structure.

Magnetic measurements show a clear downward trend in magnetic moment per Fe ion (calculated with nominal $\mathrm{Fe} \%$ and XRD unit cell volume) with increasing $\mathrm{Fe} \%$ (Fig 3a) in all synthesis methods. Magnetization of Fe doped $\mathrm{Sn}_{1-\mathrm{x}} \mathrm{Fe}_{\mathrm{x}} \mathrm{O}_{2}$-II follows a left-asymmetric curve with a maximum of $2.6 \times 10^{-3} \mathrm{emu} / \mathrm{g}$ at $1.0 \% \mathrm{Fe}$, and a minimum of $3.3 \times 10^{-4} \mathrm{emu} / \mathrm{g}$ at $20 \% \mathrm{Fe}$ (not shown). The highest magnetic moment was observed for $\mathrm{Sn}_{0.999} \mathrm{Fe}_{0.001} \mathrm{O}_{2}-\mathrm{II}$ at $1.6 \times 10^{-4} \mu_{\mathrm{B}} / \mathrm{Fe}$ ion, and the lowest observed for $\mathrm{Sn}_{0.90} \mathrm{Fe}_{0.10} \mathrm{O}_{2}$-II at $4.4 \times 10^{-7} \mu_{\mathrm{B}} / \mathrm{Fe}$ ion. Pure $\mathrm{SnO}_{2}$ samples (shown in Figure $3 \mathrm{~b}$ ) show variable magnetic saturation in different synthesis methods. Averaged over triplicate samples (to confirm reproducibility), these were: $0.72 \pm 0.01 \mathrm{memu} / \mathrm{g}\left(\mathrm{SnO}_{2}-\mathrm{IV}\right), 0.47 \pm 0.01 \mathrm{memu} / \mathrm{g}(\mathrm{I}), 0.30 \pm 0.01 \mathrm{memu} / \mathrm{g}$ (II), and $0.04 \pm 0.03 \mathrm{memu} / \mathrm{g}$ (III). No $\mathrm{SnO}_{2}$ - III samples showed ferromagnetic hysteresis, but all other methods 
demonstrate a small hysteresis with a coercive field of about 75G in all samples and remnant magnetization of about $10 \%$ of saturation (Figure 3c).

A common criticism about the magnetism of doped nanoparticles is the possibility of secondary phase formation by dopant atoms and this is difficult to rule out completely in most cases. However, a similarly prepared pure iron oxide sample (identified by XRD as ferrihydrite) was analyzed by VSM and found to have a susceptibility of $2.85 \times 10^{-6} \mathrm{emu} / \mathrm{g} * \mathrm{G}$ and a magnetic saturation of $21.77 \mathrm{emu} / \mathrm{g}$ in good agreement with those previously reported for ferrihydrite ${ }^{31,32}$ which allows for the exclusion of maghemite or magnetite phases. ${ }^{31}$ Additionally, we calculate a magnetic moment (using ferrihydrite structure ${ }^{33}$ ) of only $2.6 \times 10^{-6} \mu_{\mathrm{B}} / \mathrm{Fe}$ ion in the pure iron oxide sample, 2 orders of magnitude less than the maximum observed moment in $\mathrm{Sn}_{0.999} \mathrm{Fe}_{0.001} \mathrm{O}_{2}$-II, and very small compared to the calculated (experimental) magnetic moments of 5.92 (5.6-6.1) $\mu_{\mathrm{B}}$ and $1.73(1.8-2.1) \mu_{\mathrm{B}}$ for high spin $(\mathrm{S}=5 / 2)$ and low spin $(\mathrm{S}=1 / 2) \mathrm{Fe}^{3+}$ ions respectively in octahedral complexes reported in the literature. ${ }^{34}$ Surface spin frustration or other effects may diminish the effective moment, but these results still demonstrate by comparison to a pure iron oxide that the enhanced magnetism in low Fe \% samples is unlikely to be due to the presence of secondary phases.

The high magnetic moment per Fe ions observed at low Fe doping levels and its reduction to very low values at high Fe doping concentrations are unexpected and do not follow the expectations from models based on magnetic exchange. Our data shows that the lattice parameters, band gap and magnetic moment all show rapid increase below $\sim 2.5 \mathrm{Fe} \%$. This common behavior indicates that the observed magnetic behavior might have resulted from changes in the band structure of $\mathrm{SnO}_{2}$ due to mild Fe doping. At the ultrasmall size studied, $\sim 60 \%$ or more atoms in the NP are at the surface, and dominate the material properties. Changes in surface molecules or functional groups could modify the behavior of the surface atoms and the properties in general, including the novel magnetic behavior.

\section{Conclusions:}

$\mathrm{Sn}_{1-\mathrm{x}} \mathrm{Fe}_{\mathrm{x}} \mathrm{O}_{2}$ NPs were prepared by four different methods, varying $\mathrm{Fe} \%$ from 0-20\%. Sample characterization showed highly pure, crystalline, $2.5 \mathrm{~nm}$ single-phase cassiterite $\mathrm{SnO}_{2}$. Pure $\mathrm{SnO}_{2} \mathrm{NPs}$ showed unexpected, highly reproducible weak magnetization varying significantly with synthesis method. Data also indicate that doping with $\mathrm{Fe}<2.5 \%$ was substitutional, with the dopant primarily in the $\mathrm{Fe}^{3+}$ state; the magnetic moments in all samples with a moment per ion much greater than that of similarly prepared pure iron oxide. The enhanced moment was reduced to a value similar to pure $\mathrm{SnO}_{2} \mathrm{NPs}$ for $\mathrm{Fe} \geq 2.5 \%$. Optical bandgap measurements demonstrated significant modification of the electronic structure by both ultrasmall particle size and Fe doping. Further characterization work is in progress, employing Electron Paramagnetic Resonance and Mossbauer Spectroscopy to conclusively determine

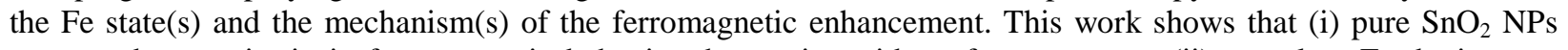
may produce an intrinsic ferromagnetic behavior that varies with surface structure, (ii) very low Fe doping can enhance magnetic moments, and (iii) higher Fe doping destroys the observed ferromagnetism. These results support the possibility that the magnetic properties of $\mathrm{SnO}_{2} \mathrm{NPs}$ results from modification of the electronic structure by dopant, size, and surface structure.

\section{Acknowledgements:}

This work was supported in part by NSF EAGER DMR-1137419, ARO W911NF-09-1-0051 and NSF CBET 1134468 grants. C.B.H. was supported by a NSF DMR-0906618 grant. 


\section{References}

M. Miyauchi, A. Nakajima, T. Watanabe, and K. Hashimoto, Chemistry of Materials 14, 2812 (2002). C. G. Granqvist, Solar Energy Materials and Solar Cells 91, 1529 (2007).

P. Alex, K. M. Reddy, T. Aaron, H. Jason, and H. E. Mark, Nanotechnology 18, 165502 (2007).

T. Dietl, H. Ohno, F. Matsukura, J. Cibert, and D. Ferrand, Science 287, 1019 (2000).

J. M. D. Coey, K. Wongsaprom, J. Alaria, and M. Venkatesan, Journal of Physics D: Applied Physics 41, 134012 (2008).

J. M. D. Coey, M. Venkatesan, and C. B. Fitzgerald, Nat Mater 4, 173 (2005).

C. B. Fitzgerald, M. Venkatesan, L. S. Dorneles, R. Gunning, P. Stamenov, J. M. D. Coey, P. A. Stampe, R. J. Kennedy, E. C. Moreira, and U. S. Sias, Physical Review B 74, 115307 (2006).

W.-Z. Xiao, L.-L. Wang, L. Xu, Q. Wan, and B. S. Zou, Solid State Communications 149, 1304 (2009).

G. Rahman and V. M. Garcia-Suarez, Applied Physics Letters 96 (2010).

W. Z. X. W. Z. Xiao, H. Luo, J. Y. Yang, and D. Shuang, European Physical Journal B 80, 337 (2011).

W. Zhou, L. Liu, and P. Wu, Journal of Magnetism and Magnetic Materials 321, 3356 (2009).

G. Rahman, Garcia-Suarez, and H. Victor M., Soon Cheol, Physical Review B 78, 184404 (2008).

Ç. Kılıç and A. Zunger, Physical Review Letters 88, 095501 (2002).

A. Sundaresan, R. Bhargavi, N. Rangarajan, U. Siddesh, and C. N. R. Rao, Physical Review B 74, 161306 (2006).

L. M. Johnson, A. Thurber, J. Anghel, M. Sabetian, M. H. Engelhard, D. A. Tenne, C. B. Hanna, and A. Punnoose, Physical Review B 82, 054419 (2010).

J. Hays, A. Punnoose, R. Baldner, M. H. Engelhard, J. Peloquin, and K. M. Reddy, Physical Review B 72, 075203 (2005).

A. P. Thurber, G. L. Beausoleil, G. A. Alanko, J. J. Anghel, M. S. Jones, L. M. Johnson, J. H. Zhang, C. B. Hanna, D. A. Tenne, and A. Punnoose, Journal of Applied Physics 109 (2010).

M. A. Garcia, J. M. Merino, E. Fernandez Pinel, A. Quesada, J. de la Venta, M. L. Ruiz Gonzalez, G. R. Castro, P. Crespo, J. Llopis, J. M. Gonzalez-Calbet, and A. Hernando, Nano Letters 7, 1489 (2007).

R. Adhikari, A. K. Das, D. Karmakar, T. V. C. Rao, and J. Ghatak, Physical Review B 78, 024404 (2008). L. M. Fang, X. T. Zu, Z. J. Li, S. Zhu, C. M. Liu, W. L. Zhou, and L. M. Wang, Journal of Alloys and Compounds 454, 261 (2008).

B. Cordero, V. Gomez, A. E. Platero-Prats, M. Reves, J. Echeverria, E. Cremades, F. Barragan, and S. Alvarez, Dalton Transactions, 2832 (2008).

S. Rani, S. C. Roy, N. Karar, and M. C. Bhatnagar, Solid State Communications 141, 214 (2007).

M. S. Castro and C. M. Aldao, Journal of the European Ceramic Society 18, 2233 (1998).

R. T. Downs and M. Hall-Wallace, American Mineralogist 88, 247 (2003).

E. Jansen, A. Kyek, W. Schäfer, and U. Schwertmann, Applied Physics A: Materials Science \& Processing 74, s1004 (2002).

D. Brion, Applications of Surface Science 5, 133 (1980).

N. S. McIntyre and D. G. Zetaruk, Analytical Chemistry 49, 1521 (1977).

J. Kang, S. Tsunekawa, and A. Kasuya, Applied Surface Science 174, 306 (2001).

J. Zhu, W. Zheng, B. He, J. Zhang, and M. Anpo, Journal of Molecular Catalysis A: Chemical 216, 35 (2004).

D. A. Popescu, J.-M. Herrmann, A. Ensuque, and F. Bozon-Verduraz, Physical Chemistry Chemical Physics 3, 2522 (2001).

S. Johari Pannalal, S. A. Crowe, M. T. Cioppa, D. T. A. Symons, A. Sturm, and D. A. Fowle, Earth and Planetary Science Letters 236, 856 (2005).

M. S. Seehra and A. Punnoose, Physical Review B 64, 132410 (2001).

F. M. Michel, L. Ehm, S. M. Antao, P. L. Lee, P. J. Chupas, G. Liu, D. R. Strongin, M. A. A. Schoonen, B. L. Phillips, and J. B. Parise, Science 316, 1726 (2007).

A. Punnoose, K. Reddy, J. Hays, A. Thurber, S. Andronenko, and S. Misra, Applied Magnetic Resonance 36, 331 (2009). 


\section{FIGURE CAPTIONS}

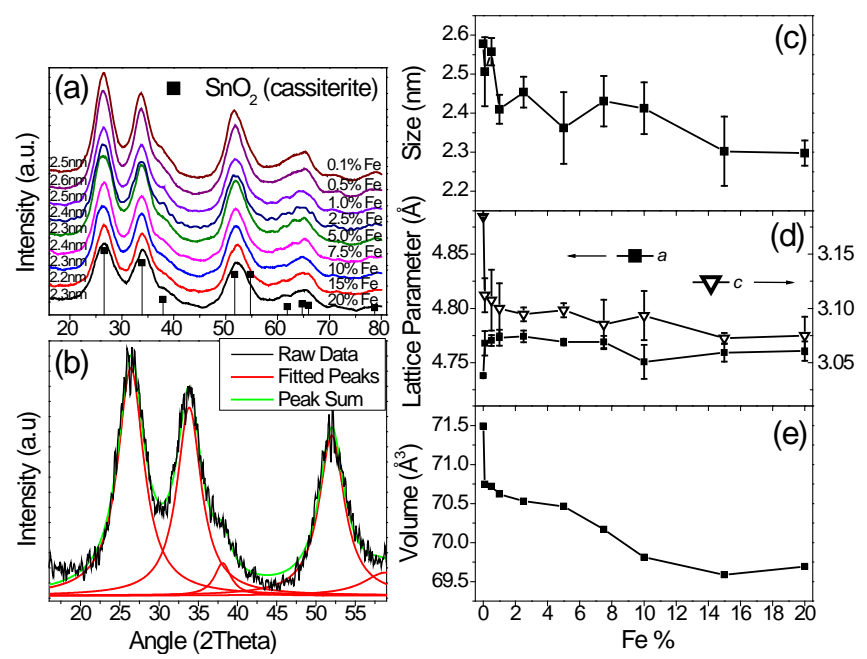

Figure 1. (Color online) XRD patterns for $\mathrm{Fe}_{\mathrm{x}} \mathrm{Sn}_{1-\mathrm{x}} \mathrm{O}_{2}$-II (a), an example simultaneous gaussian fit of $0.1 \% \mathrm{FeSnO}_{2}$-II XRD data (b), and the variation of crystallite size (c), lattice parameters (d) and cell volume (e) with Fe\%. Error bars represent triplicate trials, while the lines are a guide for the eye.
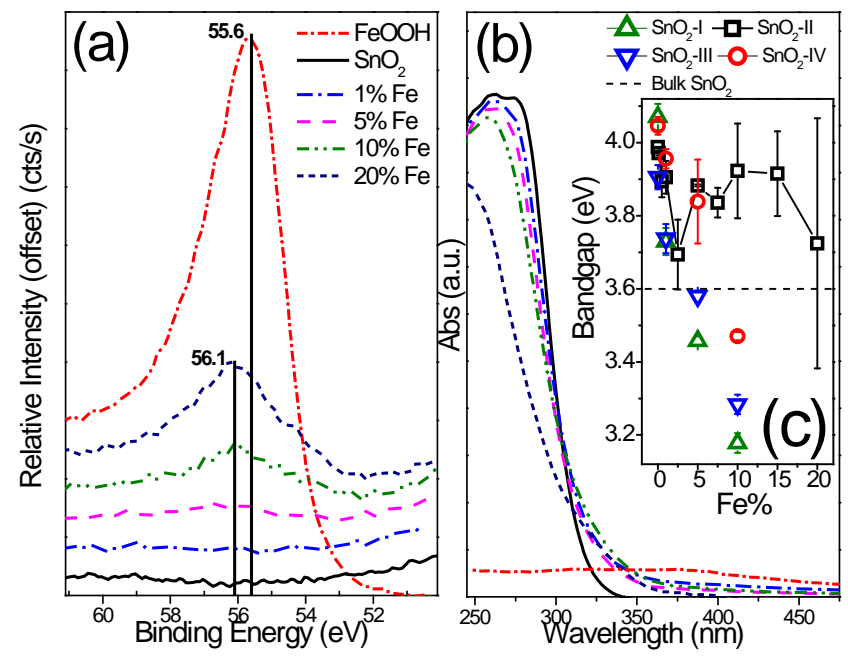
Figure 2. (Color online) XPS high-res scan of the Fe3p peak shows Fe doping in $\mathrm{Fe}_{\mathrm{x}} \mathrm{Sn}_{1-\mathrm{x}} \mathrm{O}_{2}$-II (concentrations are nominal, not measured) (a), UV-Vis photospectrometry shows shifting of absorption edge with $\mathrm{Fe} \%$ (b) and calculated bandgap variation (c). Error bars represent triplicate

trials, while the lines are a guide for the eye.

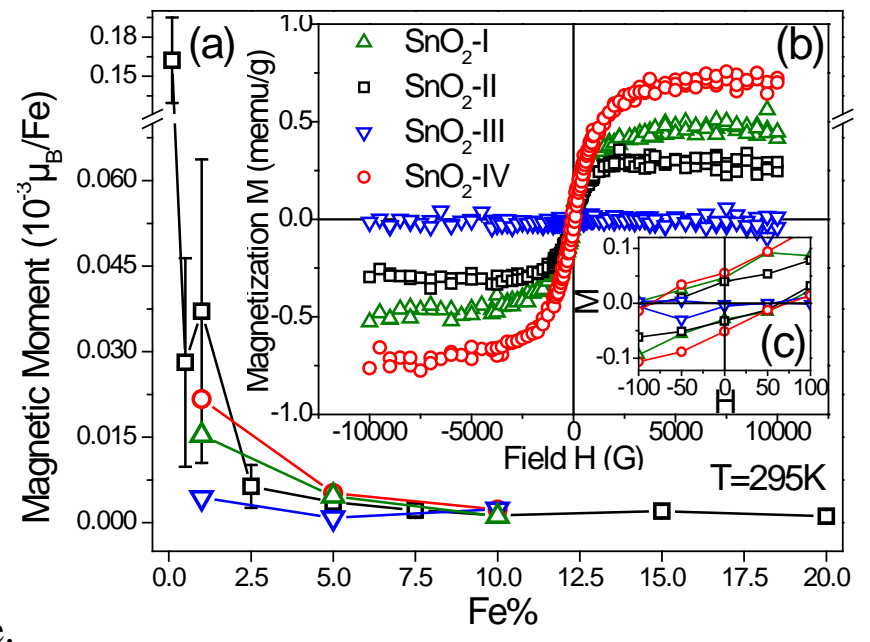

Figure 3. (Color online) Room temperature VSM measurements give the magnetic moment variation by synthesis method and $\mathrm{Fe} \%$ (a), representative $\mathrm{M}$ vs $\mathrm{H}$ plots for undoped samples in all synthesis methods (b), and their low-field regions (c). Error bars represent triplicate trials, while the lines are a guide for the eye. 